\title{
Anomalous origin of right pulmonary artery from ascending aorta - A case report
}

\author{
Manohar B Kachare'1, Vijay C Nalpe ${ }^{2}$, Ravi Raval ${ }^{3}$
}

\{1Professor and Head, 2 Junior Resident, Department of Radiodiagnosis\} \{3Associate Professor, Department of Obstetrics and Gynaecology\} Government Medical College and Hospital Miraj, M aharashtra, INDIA.

Email: vijay nalpe@yahoo.com

\begin{abstract}
Hemitruncus Arteriosus is a rare congenital anomaly associated with poor quality of life and reduced life expectancy during postnatal life. We report a case of 21 years old primigravida with $\approx 22$ weeks of gestation with anomalous origin of the right PA from the aorta that was diagnosed by fetal echocardiography. This is the fourth reported case of anomalous origin of right pulmonary artery from ascending aorta diagnosed on fetal echocardiography in the literature.

Key Word: Congenital heart disease, Anomalous pulmonary artery, Hemitruncusarteriosus.
\end{abstract}

\section{*Address for Correspondence:}

Dr. Vijay C Nalpe, S-5, Venktesh Apartment, Londhe colony, Ganesh Nagar, Miraj. Pin-416410, INDIA.

Email: vijay nalpe@ yahoo.com

Received Date: 12/02/2019 Revised Date: 28/03/2019 Accepted Date: 18/05/2019

DOI: https://doi.org/10.26611/10131031

\begin{tabular}{|l|l|}
\hline \multicolumn{2}{|c|}{ Access this article online } \\
\hline Quick Response Code: & Website: \\
\hline & www.medpulse.in \\
& \\
\hline
\end{tabular}

\section{INTRODUCTION}

The anomalous origin of one pulmonary artery branch from the ascending aorta (hemitruncusarteriosus) is an infrequent anomaly that occurs in $0.12 \%$ of patients with congenital heart disease.1It was first described by $\mathrm{O}$ Fraentzel in 1868 and more than 95\% of the reported cases of hemitruncusarteriosus diagnosed are atinfancy. 2 In this condition, one lung is supplied from the aorta, whereas the other is perfused through the main pulmonary artery, which continues as a single vessel. The prognosis of these patients is poor because of the tendency to early congestive cardiac failure, which could be fatal. It has to be early diagnosed in order to enable opportune surgical repair, due to the high risk for the development of irreversible pulmonary disease. 3

\section{CASE DESCRIPTION}

A 21 year old primigravida woman was referred for fetal echocardiography at 21 weeks 6 days amenorrhoea following routine ultrasound screening with suspected cardiac anomaly. All the fetal growth parameters were normal for gestational age. The Fetal Heart Rate (FHR) was $144 \mathrm{Bpm}$ and Effective Fetal Weight was approximately $452 \mathrm{gms}$. The family history was negative for congenital heart malformations. The heart had a normal cardiac axis with situssolitus, concordant atrioventricular, and ventriculoarterial connections. Both atria and ventricles are of same size and all the cardiac valves were of normal morphology. Foramen ovale is opening towards left side. Right pulmonary artery is arising from proximal ascending aorta and is dilated. Left pulmonary artery is arising from main pulmonary artery proximal to the ductus. Visualised both the aortic and ductal arches are normal. There is no evidence of any ventricular septal defect or coarctation of aorta noted. The key characteristic of AOPA in fetal echocardiography includes proximal ascending Aorta giving rise to Anomalous Right pulmonary artery. 


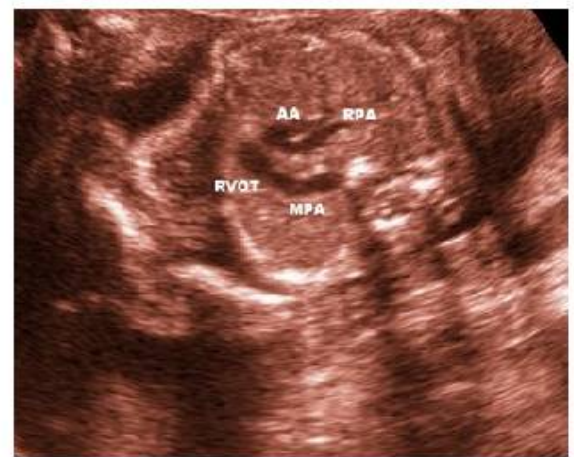

Figure 1

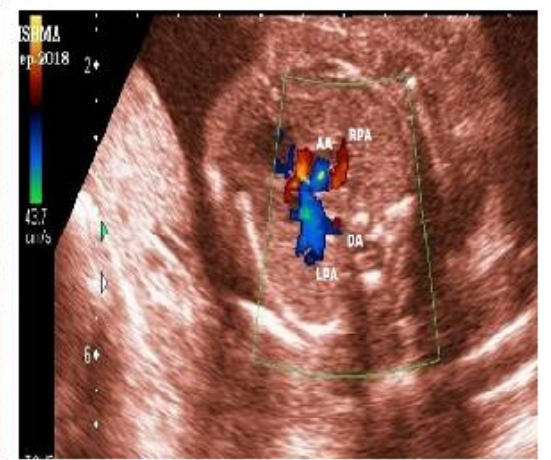

Figure 2

Figure $1 \&$ 2: B mode image of the fetal echo shows right pulmonary artery arising from ascending aorta instead of main pulmonary artery; RPA- Right pulmonary Artery; LPA- Left pulmonary Artery; AA- Ascending aorta; M PA- M ain Pulmonary artery; RVOT- Right Ventricular Outflow tract

\section{DISCUSSION}

Despite its rarity, early recognition of hemitruncusarteriosus is essential in providing optimal patient management owing to the excellent short- and long-term prognosis resulting from early corrective surgery. ${ }^{4}$ To our knowledge, there were only three cases diagnosed by fetal echocardiography. ${ }^{5}$ In the literature survey further carried out, we found only 10 cases of hemitruncusarteriosus among adults (during postnatal life) and anomalous origin of the right pulmonary branch (AORPA) is five to six times more frequent than that of the left (AOLPA). ${ }^{6}$ According to Cucciet al. ${ }^{7}$ (1964), it might be a result of faulty septation of the truncusarteriosus. This septation process starts with the appearance of two ridges within the primitive truncus, which extend from its cephalic end to the base of the conus and meet to form the truncoconalseptum. It divides the aorta from the main pulmonary artery as well as the two ventricular outflow tracts. If the right truncoconal ridgeoriginates from the primitive truncus more dorsally than normal, the proximal sixth aortic arch(and hence the right pulmonary artery) will arise from the ascending aorta. In babies with AOPA, the affected lung receives unrestricted blood at systemic pressure from the aorta, whereas the contralateral lung receives the entire right ventricular cardiac output. If left untreated, 1-year survival may be as low as $30 \%$ because of pulmonary vascular obstructive disease and heart failure. Early management of these patients results in an excellent hemodynamic and anatomic results and improved the out comes in these patients. ${ }^{8}$ It is important to distinguish this anomaly from other conotruncalmal formation, such as, pulmonary atresia, transposition of great arteries, and truncus arteriosus. ${ }^{9}$ Early diagnosis in fetal period is essential to perform early postnatal surgical repair and counsel the family at the time of diagnosis. This case will provide a learning platform to practitioners and that subsequent cases of the like should bediagnosed promptly and managed in a timely and aggressive manner.

\section{REFERENCES}

1. Kutsche LM, Van Mierop LH. Anomalous origin of a pulmonary artery from the ascending aorta: associated anomalies and pathogenesis. Am J Cardiol 1988;61(10):850-856

2. Fraentzel O. Ein Fall Von Abnormer communication Der Aorta mit der ArteriaPulmonalis. Arch PatholAnatPhysiolKlin Med. 1868; 43: 420-426.

3. Caudill, D. R., Helmsworth, J. A., Daoud, G., and Kaplan, S. (1969). Anomalous origin of the left pulmonary artery from the ascending aorta. Journal of Thoracic and Cardiovascular Surgery, 57, 493-505.

4. Peng EW, Shanmugam G, Macarthur KJ, Pollock JC. Ascending aortic origin of a branch pulmonary arterysurgical management and long-term outcome. Eur $J$ Cardiothorac Surg. 2004; 26: 762-766.

5. Diab K, Richardson R, Pophal S, Alboliras E. Left hemitruncus associated with tetralogy of fallot: fetal diagnosis and postnatal echocardiographic and cardiac computed tomographic confirmation. Pediatr Cardiol 2010;31(4):534-537

6. Nikolaidis N, Velissaris T, Haw MP. Pulmonary artery banding for hemi-truncusarteriosus in adulthood. ThoracCardiovasc Surg. 2010; 58: 181-183.

\section{Source of Support: None Declared} Conflict of Interest: None Declared 